\title{
Frank's Sign: Diagonal Earlobe Crease
}

\author{
Tom Edward Mallinson ${ }^{\dagger}$, David Brooke
}

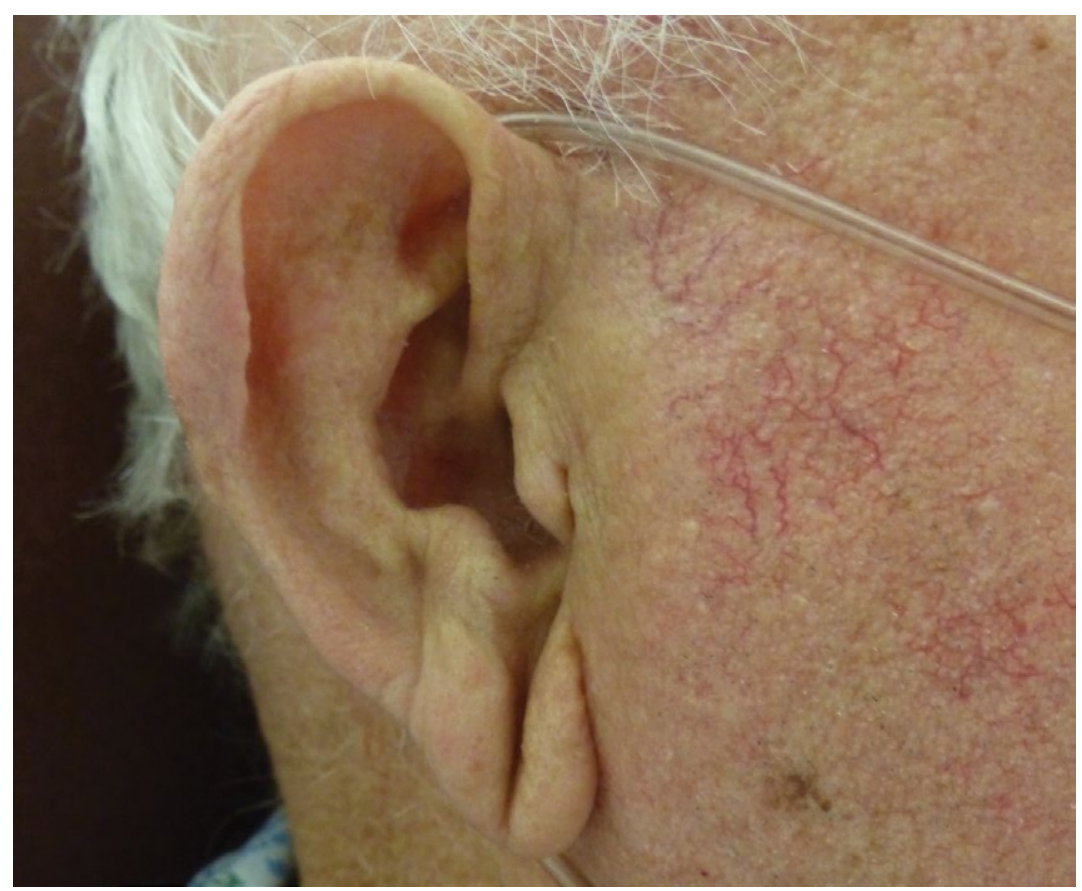

Figure 1: Pronounced Diagonal Earlobe Crease (Frank's Sign).

Given Clinical Image shows a pronounced diagonal earlobe crease (Frank's Sign) first described in 1973 [1]. Frank's Sign is strongly predictive of coronary artery disease but lacks enough specificity and sensitivity to make it pathognomonic. Frank's Sign should be looked for as an objective marker of older age, in the same way as corneal arcus, xanthelasmata and greying hair (Figure 1).

\section{References}

1. Frank ST. Aural sign of coronary-artery disease. N. Engl. J. Med 289(6), 327-328 (1973). 